\title{
Estimation of tubular differentiation in female libyan breast cancer
}

\author{
Boder M Jamela ${ }^{1,2^{*}}$, Abdalla B Fathi ${ }^{1,2}$, Elfagieh A Mohamed ${ }^{3}$ and Collan U Yrjö \\ *Correspondence: jambod@utu.fi \\ 'Department of Pathology, University of Turku, Kiinamyllynkatu 10, FIN-20520 Turku, Finland. \\ ${ }^{2}$ Department of Pathology, National Cancer Institute, Tripoli street, Misurata, Libya. \\ ${ }^{3}$ Department of Surgery, National Cancer Institute, Tripoli street, Misurata, Libya.
}

\begin{abstract}
Background: We tried to evaluate tubular differentiation in the paraffin sections of 130 Libyan breast cancers to distinguish the less aggressive variants of infiltrating breast cancer from other variants and to found the relationship with clinicopathological features. We also compared our results with corresponding results on Finnish, and Nigerian female breast cancer patients.

Methods: Histological samples from 130 patients of Libyan breast cancer were retrospectively studied by estimated the fraction of fields with tubular differentiation (FTD). The samples were screened at x10 magnification and the presence or absence of malignant tubular structures in each microscopic field was registered. They were compared with different clinicopathological features, and patient's survival.

Results: The mean $( \pm S D)$ value of FTD in Libya $23.4 \pm 21.6 \%$, was higher than in Nigeria. but lower than reported in European breast cancer. There was statistically significant correlation between the FTD and some clinicopathological features, with the strongest association observed for large tumor $(\mathrm{p}<0.0001)$. There was also correlation between FTD and histological grade $(p=0.001)$ and lymph node $(L N)$ status $(p=0.007)$. The correlation with tumor staging was almost significant $(\mathrm{p}=0.07)$.

Conclusions: The results indicated that FTD are reliable prognostic indicators in Libyan female breast carcinomas, as they were among Finnish and Nigerian females. The FTD is a good parameter for identifying the aggressive tumor phenotype and provide significant prognostic support. The cut-offs (30\% and 50\%) might be applied as quantitative criterium for Libyan breast cancer to separate the patients into good, moderate and bad prognosis groups. The survival analysis indicated that short survival time was associated with low FTD values.
\end{abstract}

Key words: Female breast cancer, fraction of fields with tubular differentiation, survival, prognosis, libya, finland, nigeria

\section{Background}

Breast cancer is the most common cancer in women in the world. It is also the most cause of deaths among female cancers patients [1,2]. Breast cancer is actively studied, but many aspects still remain unclear, including the special features associated with individual countries. The breast cancer prognosis can be evaluated by traditional features such as tumor size, and lymph node status [3]. The histological grading system is also associated with high prognostic potential [4], but is still subjective, and leaves a large group of patients with unclear prognosis [5]. Quantitative histopathology can be expected to be more reproducible than the subjective methods [6]. Earlier studies in breast cancer have suggested that there are variations in nuclear size features, proliferative and apoptotic activity. It is not well known, however, how these differences are reflected in tubular differentiation.

Many studies have suggested that tubular differentiation could have potential as a prognosticator in different adenocarcinomas [7-9]. Other studies, however, do not agree [10-14]. The aim of this study is to focus on the role of TFD in the evaluation of Libyan breast cancer prognosis and the relation of TFD with clinicopathological features. We found this research attractive because through such a study we could compare Libyan breast cancers with those from Finnish (European) and Nigerian (Central African) patients, after we used same method described by Kronqvist et al., [15] and Ikpatt et al., [21].

\section{Methods}

The study was performed on paraffin embedded Libyan female breast cancer samples. All cases were diagnosed at the Department of Pathology, African Oncology Institute, Sabratha, Libya, and Tripoli Medical Centre, Tripoli, Libya during the years 2000 - 2006. Patients were excluded from this study on the basis of the following exclusion criteria: histopathology was done elsewhere than in the mentioned study centres, patient history and medical files, or specimens were not found, the follow up was less than 3 months, paraffin blocks were not available for re-cutting. After exclusion of patients 130 patients remained in the study. 115 patients were treated with modified radical mastectomy with axillary clearance. 15 patients were unfit for surgery due to distant metastases;

(C) 2013 Jamela et al; licensee Herbert Publications Ltd. This is an Open Access article distributed under the terms of Creative Commons Attribution License (http://creativecommons.org/licenses/by/3.0). This permits unrestricted use, distribution, and reproduction in any medium, provided the original work is properly cited. 
Jamela et al. Journal of Cancer Therapeutics \& Research 2013, http://www.hoajonline.com/journals/pdf/2049-7962-2-5.pdf

doi: 10.7243/2049-7962-2-5

Table 1. Fraction of fields with tubular differentiation (FTD) in 130 Libyan histological breast cancer samples, and in different subgroups defined by menopausal status, tumor size, lymph node status, clinical stage, histological grade, and histological type. The feature values are presented as means with the SD. The p-values refer to significance ofdifference between the subgroups (based on $\mathrm{T}$ test and analysis of variance, ANOVA).

\begin{tabular}{|c|c|c|c|}
\hline Group & o. of patients & $\operatorname{Mean}(\mathrm{SD})$ & P value \\
\hline Whole material & 130 & $23.4(21.6)$ & - \\
\hline \multicolumn{4}{|l|}{ Menopausal status } \\
\hline $\begin{array}{l}\text { Premenopausal } \\
\text { (age < } 50 \text { years) }\end{array}$ & 80 & $25.3(22.8)$ & \multirow[t]{2}{*}{0.22} \\
\hline $\begin{array}{l}\text { Postmenopausal } \\
\text { (age } \geq 50 \text { years) }\end{array}$ & 50 & $20.5(19.4)$ & \\
\hline$\leq 5.5 \mathrm{~cm}$ & 98 & $27.4(22.5)$ & $<0.0001$ \\
\hline$>5.5 \mathrm{~cm}$ & 32 & $11.3(12.5)$ & - \\
\hline \multicolumn{4}{|l|}{ Lymph node (LN) status } \\
\hline $\mathrm{LN}+$ & 103 & $20.8(20.1)$ & - \\
\hline $\begin{array}{l}\text { Clinical stage } \\
\text { Early stage }(1,2)\end{array}$ & 50 & $27.7(21.9)$ & 0.07 \\
\hline Advanced stage $(3,4)$ & 80 & $20.8(21.1)$ & - \\
\hline \multicolumn{4}{|l|}{ Histological grade } \\
\hline Grade 2 & 70 & $26.1(23.5)$ & - \\
\hline Grade 3 & 50 & $16.1(16.5)$ & - \\
\hline \multicolumn{4}{|l|}{ Histological type } \\
\hline Other types & 35 & $25.7(23.8)$ & - \\
\hline
\end{tabular}

diagnostic biopsies were used in this study. A detailed history, clinicopathological features (age, menopausal status, tumour size, stage and grade, and lymph node status, follow up data) were collected from patients files (Table 1 and 2). Age of the patients ranged from 25 to 85 years with a mean age at the time of diagnosis was 46.7(SD \pm 13.4 ) years. $4.6 \%, 34.6 \%, 48.5 \%$ and $12.3 \%$ of patients were at stages $1,2,3$, and 4, respectively.

Follow up time ranged from 4 to 72 months, Average follow up was 32 months.

The distribution of age, axillary lymph node status, stage, histological type, and histological grades are shown in (Table 1). Mean nuclear area, mitotic and apoptotic indices were evaluated from $\mathrm{H}$ \& E sections as described earlier $[16,17]$.

\section{Histological methods}

All biopsy specimens were fixed in buffered formalin, and embedded in paraffin. Sections $5 \mu \mathrm{m}$ thick were stained with hematoxylin and eosin stain. The histological typing in our study was based on the International Histological Classification of Tumours [18], and grading of tumours was done according the modified Bloom-Richardson histopathological grading system [19].

Tubular differentiation was evaluated in each sample as the fraction of fields showing tubular differentiation (FTD) $[15,20]$. According to this method tubular differentiation
Table 2. Univariate analyses performed in the whole material and in different sub groups on the most important prognosticators.

\begin{tabular}{|c|c|c|}
\hline Group of patient & Prognostic feature & p-value \\
\hline \multirow[t]{7}{*}{ All patient $(n=130)$} & $\begin{array}{l}\text { FTD } 30 \\
\text { FTD } 50\end{array}$ & $\begin{array}{c}0.002 \\
0.02\end{array}$ \\
\hline & SMI 44 & $<0.0001$ \\
\hline & MAI 15 & $<0.0001$ \\
\hline & Menopausal status & 0.02 \\
\hline & LN status & $<0.0001$ \\
\hline & T stage & $<0.0001$ \\
\hline & $\begin{array}{l}\text { M stage } \\
\text { Grade }\end{array}$ & $\begin{array}{c}<0.0001 \\
0.003\end{array}$ \\
\hline \multirow[t]{8}{*}{ Premenopausal $(\mathrm{n}=80)$} & FTD30 & 0.003 \\
\hline & FTD50 & 0.25 \\
\hline & SMI 44 & $<0.0001$ \\
\hline & MAI 15 & $<0.0001$ \\
\hline & LN status & $<0.0001$ \\
\hline & T stage & $<0.0001$ \\
\hline & $\mathrm{M}$ stage & 0.027 \\
\hline & Grade & 0.004 \\
\hline \multirow{8}{*}{ Postmenopausal $(\mathrm{n}=50)$} & FTD30 & 0.54 \\
\hline & FTD50 & 0.24 \\
\hline & SMI 44 & 0.09 \\
\hline & MAI 15 & 0.8 \\
\hline & LN status & 0.1 \\
\hline & T stage & 0.04 \\
\hline & M stage & $<0.0001$ \\
\hline & Grade & 0.6 \\
\hline \multirow[t]{7}{*}{ Positive LN (n=103) } & FTD30 & 0.28 \\
\hline & FTD50 & 0.17 \\
\hline & SMI 44 & 0.01 \\
\hline & MAI 15 & 0.02 \\
\hline & T stage & 0.002 \\
\hline & M stage & $<0.0001$ \\
\hline & Grade & 0.13 \\
\hline \multirow[t]{7}{*}{ Negative LN (n=27) } & FTD30\% & 0.1 \\
\hline & SMI 44 & 0.7 \\
\hline & MAI 15 & 0.1 \\
\hline & MAI58 & 0.7 \\
\hline & T stage & 0.7 \\
\hline & M stage & NA \\
\hline & Grade & 0.7 \\
\hline
\end{tabular}

was assessed in the whole tumour area. The samples were screened at $\times 10$ magnification and the presence or absence of malignant tubular structures in each microscopic field was registered. By this method the field was registered positive if a single undoubable malignant tubular structure was identified. The final result was the fraction of fields presenting tubular differentiation. This assessment method is especially recommended because it has turned out to be the most efficient and fastest way to evaluate in quantitative terms the tubular differentiation in invasive breast cancer. In a previous study [15] on Finnish material comparing several evaluation methods for tubular differentiation [20], FTD showed out to be the most practical, accurate and reproducible way to determine tubular differentiation in invasive breast cancer. In the evaluations, special emphasis was placed on histological identification of the malignant tubule. The required features for registering a tubule was a clear lumen within a tubular or alveolar pattern created by surrounding malignant epithelial cells. Special consideration was taken to avoid 


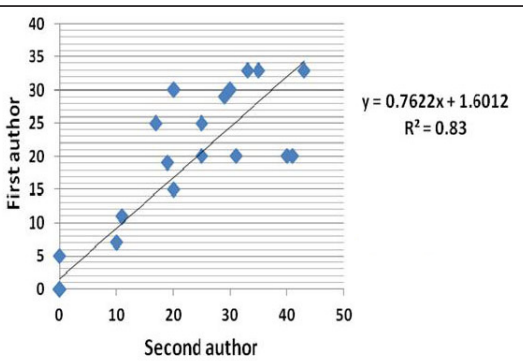

Figure 1. Correlation between two observers in estimating FTD in 30 Libyan female breast cancers. Clearly, there is significant correlation $(\mathrm{P}<0.0001)$, (Pearson's correlation). a little acceptable variation between two observes are seen in upper region, which usually obtained from the cases that have a large sections.

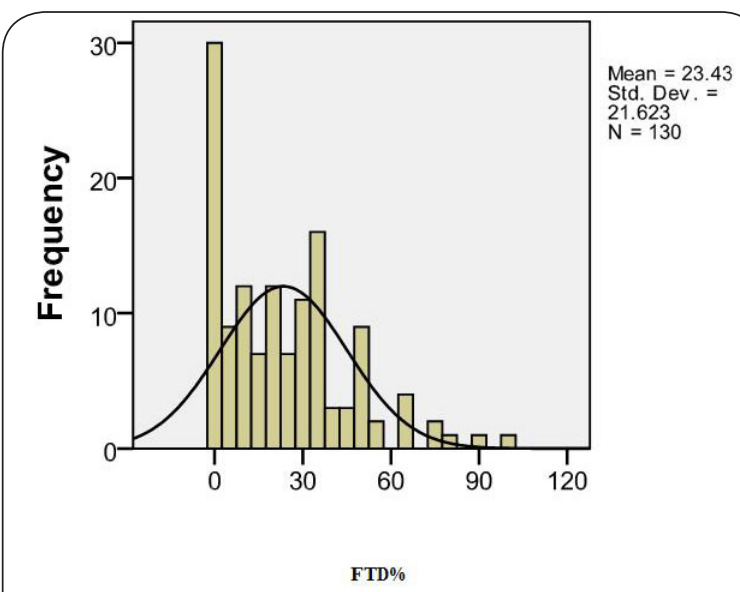

Figure 2. Distribution of FTD values in 130 Libyan female breast cancers. The mean FTD value was 23.43.
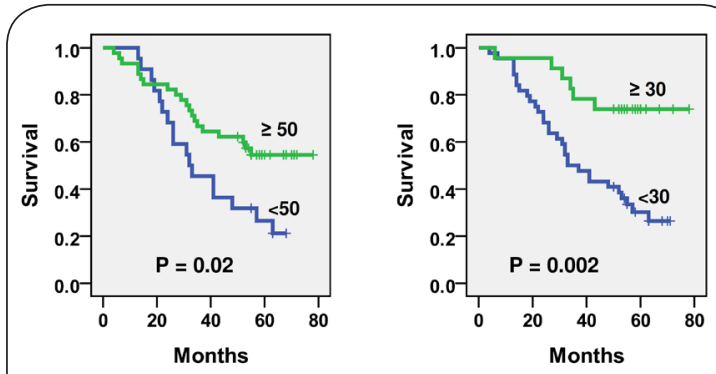

Figure 3. Survival curves for 130 Libyan female patients with breast cancer divided by FTD cut points of $30 \%$ and $50 \%$. The differences between the curves are highly significant (log-rank test $=0.002$, 0.02 respectively) especially after the 40 months of follow-up.

counting adipocytes, benign ducts, central necrosis or artefact clefts as malignant tubules. Luminal structures in cribriform malignant epithelium were also not counted.

\section{Statistical analysis}

The variables of the material were grouped into logical classes and descriptive statistics calculated for both grouping and continuous variables using SPSS 19.0 for
Windows. For survival analysis, Kaplan Meier curves were plotted, and differences between the curves analyzed using the log-rank test. The FTD cut-off points were tested for association with survival using a log-rank test. Survival analysis was performed with Cox proportional hazard model. Univariate analyses were carried out on all patients and on subgroups classified by menopausal status (pre and postmenopausal) and by axillary lymph node status (node positive $\mathrm{N}+$, node negative $\mathrm{N}$-). To evaluate the independency association of FTD and survival among the other prognosticators, the Cox multivariate regression model was used.

P-values below 0.05 were regarded as significant. Student t-tests and ANOVA were also used to test differences between the groups.

\section{Results}

Inter observer variation in estimation of the FTD

First and second authors were estimated the fraction of fields with tubular differentiation in 30 samples of Libyan female BCs. Figure 1 shows a strong correlation between two observers. Clearly, there is high reproducibility and with high significance value $(P<0.0001)$, (Pearson's correlation 0.91 , Kappa statistic $=0.55$ ).

\section{Correlation of FTD with the clinicopathological features}

The clinical characteristics of the Libyan female BC patients $(n=130)$ and average estimate of FTD is described in Table 1 and $\mathbf{2}$. The distributions of the values are shown in Figure 2. The mean fraction of FTD in our material was $23.4 \%$ (median $20.0 \%$, standard deviation $21.6 \%$ ).

There was statistically significant correlation between the FTD and some clinicopathological features, with the strongest association observed for tumor larger than the mean $(\mathrm{p}<$ $0.0001)$. Higher values are also seen in patients with high histological grade, and those of positive lymph nodes and advanced clinical stage with (P values $0.001,0.007$ and 0.07 , respectively). The difference in the FTD between invasive ductal carcinoma and other types of breast carcinomas was statistically insignificant $(P=0.46)$ (Table 1$)$.

\section{Correlation of FTD with the survival outcome}

The FTD can identify aggressive tumors and provide significant prognostic support. Kaplan-Meier curves of FTD indicated that better survival time was correlated with high FTD tumors (Figure 3). However, in multivariate analysis (all patients, with SMI, MAl, nuclear area and apoptotic count) FTD was not significant. The cut-offs (30\% and $50 \%$ ) can be considered to represent the most reliable thresholds for classifying patients according to tubular differentiation with ( $p$ value $=0.002$, and 0.02 respectively) . and might be applied as quantitative criterium for Libyan breast cancer to separate the patients into good $(\geq 50)$, moderate (30-50), and bad prognosis group $(<30)$ (Figure 3). FTD30\% thresholds could be detected also in analyses of pre-menopausal patients (Table 2). No statistically significant threshold could be found among the other prognostic subgroups, however, FTD30\% was detected as the only almost significant cut off in axillary 
Table 3. Univariate analysis (Cox regression model) of all tested prognostic factors in whole Libyan material (number of patients $=130$ ) using the prognostic factors as acontinuous variable.

\begin{tabular}{lccc}
\hline & p value & Risk Ratio & $\mathbf{9 5 . 0 \%}$ CI \\
\hline MAI & 0.026 & 1.016 & $1.002-1.030$ \\
SMI & $<0.0001$ & 1.020 & $1.009-1.030$ \\
MNA & 0.015 & 1.020 & $1.004-1.036$ \\
AI & 0.003 & 1.042 & $1.014-1.071$ \\
FTD & 0.038 & 0.981 & $0.964-0.999$ \\
\hline
\end{tabular}

Table 4. Multivariate analysis (Cox regression model) of all tested prognostic factors in whole Libyan material (number of patients $=130$ ) using the prognostic factors as a continuous variable.

\begin{tabular}{lccc}
\hline & p value & Risk Ratio & $\mathbf{9 5 . 0 \%}$ CI \\
\hline AI & 0.504 & 1.012 & $0.978-1.047$ \\
SMI & 0.039 & 1.015 & $1.001-1.030$ \\
MAI & 0.723 & 1.003 & $0.986-1.021$ \\
MNA & 0.134 & 1.014 & $0.996-1.033$ \\
FTD & 0.353 & 0.991 & $0.972-1.010$ \\
\hline
\end{tabular}

lymph node-negative patients. Table 3 summarizes the relative risks (RRs) of univariate analyses describing the risk of breast cancer death associated with continuous variables in results of the whole material. FTD is a predictor of survival and the patients with high FTD have a lower risk of breast cancer death. In general the FTD as a prognosticator is less efficient than the SMI, MAI, and MNA. In N+ patients the $\mathrm{SMI}$ and MAl were the only significant prognosticators in addition to stage. SMI was also of border line significance among postmenopausal patient (Table 2). Multivariate analysis with FTD, MNA, FTD, Al, MAI, and SMI in all patients showed that the SMI was the only significant prognosticator $(p=0.039)$ (Table 4).

\section{Discussion}

The differences between African and European breast cancers have recently emerged [16,21-24]. This study is a part of our effort to further clarifying the biology of Libyan $\mathrm{BC}$ and to comparing our results with the corresponding results of North European, and Central African female $B C$ patients. We also wanted to identify more effective prognostic factors than the traditional grading system to aid therapeutic decision making. In this study it was our intention to study the Libyan breast cancer in respect to tubular differentiation.

The mean value of FTD in Finland was 30.0\% (SD 28.2\%). This was higher than the Libyan FTD mean value $23.4 \%$ (SD 21.6\%). In Nigerian material the mean FTD value was 16.7\% (SD19.3\%), clearly lower than the Libyan FTD figure $[15,21]$. The differences in FTD between Libyan and Nigerian tumours and between Libyan and Finnish tumors were significant in the whole material $(p<0.0001,0.01)$. Basically our results on FTD reflect the same differences between countries in proliferative and apoptotic indices in previous work, although, the significant differences between Libyan and Finnish populations are less obvious.

These differences might be due to the fact that screening programmes were established in European countries for early detection of cancer. The African females came to the hospital in very advanced disease. For example the clinicopathological data of Libyan patients confirmed the aggressive nature characterizing this type of carcinoma. In Libya $49 \%$ of cases showed stage III, $80 \%$ were with LN metastasis. In the future, after establishment of screening programs in Libya, the cut point might equal that in European population. On other hand, the FTD difference between Central African, North African and European patients further strengthens our previous suggestion of biological differences and variation in genetic marker distribution between Central and North African, and European populations $[16,17,22]$ may be involved. The variation in the distribution of different genetic marker haplotypes makes this easily understandable. There is a clear difference between the marker haplotype distribution in western central Africa and northern Africa. A similar difference is to be found between North Africa and Europe $[\mathbf{2 2}, \mathbf{2 5}]$. The variation in haplotype marker distribution has taken place under selective environmental stresses and may be associated with radiation, viral association and life style [25].

Several authors have reported on the prognostic value of the FTD in breast carcinoma $[26,7,9]$. On the other hand, there are a lot of papers concluding that tubular differentiation lacks prognostic significances and is inferior to the proliferative activity and nuclear size features [10-14,27-29]. The multivariate analysis of the present study, and study of Ikpatt et al., shows that the FTD is a weak prognostic factor in relation to the proliferative and apoptotic indices. Kronqvist et al., [15] did their work by the same methodology and found that the FTD was an independent prognosticator in Finnish breast cancer. The difference in significance was smaller than in proliferative indices.

It is obvious that FTD can be used as a general prognosticator. However, mitotic activity (SMI, standardized mitotic index) is a better general prognosticator than the FTD. But FTD can add some valuable prediction particularly in premenopausal patients, when their tumours are large. The present study suggested two significant cut points for the FTD in Libyan material (30\% and 50\%) that could separate patients into three subgroups with favourable, intermediate and unfavourable prognosis (Figure 3). These cut points may be more suitable for the Libyan material than the cut points that used by Kronqvist et al., 2000 on Finnish material (23\% and 59\%).

From among five prognostic markers (MNA, Al, MAI, SMI, and FTD) the SMI and MAI were significant as general 
prognosticators, but the others were not (Table 2,3,4). This seems to be in line to earlier studies on African material [21].

\section{Conclusions}

For prognostic purposes, FTD can be used as a prognostic tool, low FDT shows association with aggressive tumour nature, and poor survival. Furthermore, in Libyan patients the FTD $(30 \%, 50 \%)$ could be used as thresholds for separation of patients into three groups with good, moderate and poor prognosis. A positive correlation between the FTD and clinicopathological features was observed, and the FTD showed the strongest correlation with tumour size and grade.

\section{Competing interests}

The authors declare that they have no competing interests.

\section{Authors' contributions}

JB designed the lab works and estimated the fraction of fields with tubular differentiation, performed research and wrote the first draft of the manuscript and gave final approval of the version to be published. FA participated in the interobserver estimation and performed the statistical analysis. ME conceived of the study, and participated in the organizing of clinical data. YC participated in the design and coordination of the study and reviewed the first draft. All authors read and approved the final manuscript.

\section{Acknowledgement}

The authors acknowlede Sinikka Kollanus for her technical work. The authors grateful to the National Cancer Institute of Misurata, Libya and Universuty of Turku, Finland for their support of this study, in providing the research facilities and help in the publication of this work.

\section{Publication history}

Received: 28-Oct-2012 Revised: 08-Dec-2012

Accepted: 15-Dec-2012 Published: 28-Jan-2013

\section{References}

1. Lester J: Breast cancer in 2007: incidence, risk assessment, and risk reduction strategies. Clin J Oncol Nurs 2007, 11:619-22. | Article | PubMed

2. Draper L: Breast cancer: trends, risks, treatments, and effects. AAOHN J 2006, 54:445-51; quiz 452-3. | PubMed

3. McBride R, Hershman D, Tsai WY, Jacobson JS, Grann V and Neugut Al: Within-stage racial differences in tumor size and number of positive lymph nodes in women with breast cancer. Cancer 2007, 110:1201-8. | Article | PubMed

4. Collan, Y., Kuopio, T., and Alanen, K: Scope and concepts of quantitive histopathology. Acta Stereol 1992, 11: 3-23. | Article

5. Page DL: Prognosis and breast cancer. Recognition of lethal and favorable prognostic types. Am J Surg Pathol 1991, 15:334-49. | Article | PubMed

6. Frierson HF, Jr., Wolber RA, Berean KW, Franquemont DW, Gaffey MJ, Boyd JC and Wilbur DC: Interobserver reproducibility of the Nottingham modification of the Bloom and Richardson histologic grading scheme for infiltrating ductal carcinoma. Am J Clin Pathol 1995,
103:195-8. | Article | PubMed

7. Fisher ER: Prognostic and therapeutic significance of pathological features of breast cancer. NCI Monogr 1986, 29-34. | PubMed

8. Theissig F, Kunze KD, Haroske G and Meyer W: Histological grading of breast cancer. Interobserver, reproducibility and prognostic significance. Pathol Res Pract 1990, 186:732-6. | Article | PubMed

9. Dalton LW, Page DL and Dupont WD: Histologic grading of breast carcinoma. A reproducibility study. Cancer 1994, 73:2765-70. | Article | PubMed

10. Baak JP, Van Dop H, Kurver PH and Hermans J: The value of morphometry to classic prognosticators in breast cancer. Cancer 1985, 56:374-82. | Article | PubMed

11. Clayton F: Pathologic correlates of survival in $\mathbf{3 7 8}$ lymph node-negative infiltrating ductal breast carcinomas. Mitotic count is the best single predictor. Cancer 1991, 68:1309-17. | Article | PubMed

12. Lipponen PK, Collan Y and Eskelinen MJ: Volume corrected mitotic index (M/V index), mitotic activity index (MAI), and histological grading in breast cancer. Int Surg 1991, 76:245-9. | Article | PubMed

13. Parham DM, Hagen $N$ and Brown RA: Simplified method of grading primary carcinomas of the breast. J Clin Pathol 1992, 45:517-20. | Article | PubMed Abstract | PubMed Full Text

14. Schumacher M, Schmoor C, Sauerbrei W, Schauer A, Ummenhofer L, Gatzemeier W and Rauschecker H: The prognostic effect of histological tumor grade in nodenegative breast cancer patients. Breast Cancer Res Treat 1993, 25:235-45. | Article | PubMed

15. Kronqvist $P$, Kuopio $T$ and Collan $Y$ : Morphometric grading of breast cancer: thresholds for tubular differentiation. $\mathrm{Br}$ J Cancer 2000, 82:1656-61. | Article | PubMed Abstract | PubMed Full Text

16. Boder J, Abdalla F, Elfagieh M, Buhmeida A and Collan Y: Apoptotic activity in Libyan breast cancer. World J Surg Oncol 2012, 10:102. | Article | PubMed Abstract | PubMed Full Text

17. Abdalla F, Boder J, Markus R, Hashmi H, Buhmeida A and Collan Y: Correlation of nuclear morphometry of breast cancer in histological sections with clinicopathological features and prognosis. Anticancer Res 2009, 29:1771-6. | Article I PubMed

18. Bocker W: [WHO classification of breast tumors and tumors of the female genital organs: pathology and genetics]. Verh Dtsch Ges Pathol 2002, 86:116-9. | PubMed

19. Elston CW and Ellis IO: Pathological prognostic factors in breast cancer. I. The value of histological grade in breast cancer: experience from a large study with long-term followup. Histopathology 1991, 19:403-10. | Article | PubMed

20. Kronqvist $P$, Kuopio $T$, Pirvu $C$ and Collan $Y$ : The fraction of fields showing neoplastic tubules: a practical estimate of tubular differentiation in breast cancer. Histopathology 1999, 35:401-10. | Article | PubMed

21. Ikpatt OF, Kuopio T, Collan Y and Ndoma-Egba R: Tubular differentiation in African breast cancer. Adv Clin Path 2003, 7:27-32. | PubMed

22. Boder JM, Elmabrouk Abdalla FB, Elfageih MA, Abusaa A, Buhmeida $A$ and Collan Y: Breast cancer patients in Libya: Comparison with European and central African patients. Oncol Lett 2011, 2:323-330. | Article | PubMed Abstract | PubMed Full Text 
23. Simon MS and Severson RK: Racial differences in breast cancer survival: the interaction of socioeconomic status and tumor biology. Am J Obstet Gynecol 1997, 176:S233-9. | $\underline{\text { Article | PubMed }}$

24. Hall IJ, Newman B, Millikan RC and Moorman PG: Body size and breast cancer risk in black women and white women: the Carolina Breast Cancer Study. Am J Epidemiol 2000, 151:754-64. | Article | PubMed

25. Jobling MA, Hurles $M$, Tyler-Smith C: Human evolutionary genetics. Origin, peoples and disease. Garland Scince Taylor and Francis group, New York and Abingdon 2004, 1-523.

26. Davis BW, Gelber R, Goldhirsch A, Hartmann WH, Hollaway L, Russell I and Rudenstam CM: Prognostic significance of peritumoral vessel invasion in clinical trials of adjuvant therapy for breast cancer with axillary lymph node metastasis. Hum Pathol 1985, 16:1212-8. | Article | PubMed

27. Rank F, Dombernowsky P, Jespersen NC, Pedersen BV and Keiding N: Histologic malignancy grading of invasive ductal breast carcinoma. A regression analysis of prognostic factors in low-risk carcinomas from a multicenter trial. Cancer 1987, 60:1299-305. | Article | PubMed

28. Le Doussal V, Tubiana-Hulin M, Friedman S, Hacene K, Spyratos $F$ and Brunet $M$ : Prognostic value of histologic grade nuclear components of Scarff-Bloom-Richardson (SBR). An improved score modification based on a multivariate analysis of $\mathbf{1 2 6 2}$ invasive ductal breast carcinomas. Cancer 1989, 64:1914-21. | Article | PubMed

29. van der Linden JC, Lindeman J, Baak JP, Meijer CJ and Herman CJ: The Multivariate Prognostic Index and nuclear DNA content are independent prognostic factors in primary breast cancer patients. Cytometry 1989, 10:56-61. | Article | PubMed

\section{Citation:}

Jamela BM, Fathi AB, Mohamed EA and Yrjö CU: Estimation of tubular differentiation in female libyan breast cancer. journal of Cancer Therapeutics and Research 2013, 2:5. http://dx.doi.org/10.7243/2049-7962-2-5 